\title{
Are tax revenue elasticities consistent with a balanced government budget? An analysis and implications for six CEE countries
}

\author{
Charalambos Pattichis*
}

York St John University, UK

Received: 18 June 2021

Revised: 28 September 2021

Accepted: 13 October 2021

\begin{abstract}
Tax revenue elasticities are an important parameter in the management of the revenue side of the government budget as they provide information about the impact of economic growth on tax revenues and fiscal sustainability. A growing number of empirical studies have estimated such elasticities or tax buoyancies for different countries using various methods. This paper follows a novel approach of deriving tax revenue elasticities that are consistent with a balanced budget for six Central and Eastern European countries using data over the period 1995-2019. These derived elasticities were then compared to actual estimates reported in other studies. The main conclusion from this comparison is that, for most cases considered, tax revenues were responsive enough to economic growth to support fiscal sustainability.
\end{abstract}

Keywords: Tax revenue elasticities; Tax buoyancy; Fiscal sustainability

JEL Classification Codes: E62, H20, H60, H68

\section{Introduction}

Tax revenue elasticities measure the responsiveness of tax revenue to a change in income. As such, they are an important parameter in the management of the revenue side of public finances. A growing literature has emerged that estimates such elasticities using various methods, see for example, Lagravinese et al. (2020), Mourre and Princen (2019), Deli et al. (2018), Dudine and Jalles (2018), Koester and Priesmeier (2017), and Belinga et al. (2014). This literature is briefly discussed in the next section. Some of the contributions in the literature focus on estimating elasticities of the various tax revenue categories (e.g., personal income taxes, corporate income taxes, indirect taxes, etc) while others focus on the overall elasticity of total tax revenue. There are also studies that estimate both. In the present paper, the focus is on the responsiveness of total tax revenue to a change in aggregate income. This income elasticity measures the percentage change in total tax revenue resulting from a given percentage change in aggregate income.

\footnotetext{
* Corresponding author. E-mail: c.pattichis@yorksj.ac.uk.
}

Citation: Pattichis, C. (2022) Are tax revenue elasticities consistent with a balanced government budget? An analysis and implications for six CEE countries, Economics and Business Letters, 11(1), 33-40.

DOI: $10.17811 /$ ebl.11.1.2022.33-40 
In contrast to the existing empirical literature, though, the aim of this paper is not to estimate econometrically the actual tax revenue elasticities. Instead, this paper follows a different methodology of deriving tax revenue elasticities that are consistent with a balanced government budget by utilising a recent contribution by Bajo-Rubio (2014). In the analysis, these derived elasticities are compared to the actual elasticities estimated in other studies and the implications for long-run fiscal sustainability are discussed. In summary, the main finding of this paper is that, in most cases, tax revenues were responsive enough to economic growth to help support fiscal sustainability.

This paper focuses on six Central and Eastern European (CEE) countries: Bulgaria, Croatia, Czechia, Hungary, Poland, and Romania. These countries are members of the European Union but have not yet adopted the euro as their currency. In a previous paper, Pattichis (2020) has used the framework proposed by Bajo-Rubio (2014) to calculate government balanceconsistent economic growth rates for the euro area countries. Although the present paper utilises the same framework (of Bajo-Rubio, 2014), it differs in approach from Pattichis (2020) in that it derives tax revenue elasticities consistent with a balanced government budget rather than economic growth rates.

The remainder of this paper is organised as follows: the next section briefly discusses some relevant literature and the adopted methodology; section 3 presents and discusses the results; and the final section offers some concluding remarks.

\section{Relevant literature and methods}

The literature in this area distinguishes between tax elasticities and tax buoyancies, with some studies estimating the former while others estimating the latter. The distinction between the two is discussed in many studies, see for example, Lagravinese et al. (2020), Mourre and Princen (2019), Deli et al. (2018), and Koester and Priesmeier (2017). As argued by these authors, although both concepts are very similar in terms of their basic conceptual definition (and often used interchangeably in many studies), the main difference is that tax elasticities are estimated after the tax revenue data has been corrected for discretionary tax policy changes. Tax buoyancies, on the other hand, measure the overall effect on tax revenue from a change in aggregate income and capture both discretionary and automatic growth of tax revenue. Lagravinese et al. (2020) have argued that even though tax elasticities may be superior for the purpose of forecasting tax revenue, "tax buoyancy may give, instead, a more comprehensive information about the long-run sustainability of the tax systems" (Lagravinese et al., 2020, pg. $3)$. In the present paper, we use both concepts interchangeably.

As noted by many authors (see, amongst others, Dudine and Jalles, 2018; Jalles, 2017; Belinga et al., 2014), long-run tax buoyancy provides information about the impact of economic growth on the long-run sustainability of the budget balance since a high long-run tax buoyancy suggests that tax revenue is very responsive to changes in aggregate income (usually proxied by Gross Domestic Product (GDP)). As Dudine and Jalles (2018), Jalles (2017) and Belinga et al. (2014) argue, if the long-run tax buoyancy is greater than 1, then the percentage change in tax revenue is greater than the rate of economic growth and this may, other things remaining the same, help improve the fiscal balance through its positive effect on the revenue side of the budget. Thus, a tax buoyancy greater than 1 implies that economic growth has positive implications for (i.e., helps improve/support) long-run fiscal sustainability and a tax buoyancy smaller than 1 has negative implications. As noted by, for example, Lagravinese et al. (2020), the theoretical expectation is that the equilibrium value of tax buoyancy in the long-run should be equal to 1 , since any other value would imply that the ratio of taxes to income will either continuously increase or continuously decrease. As Lagravinese et al. (2020) also noted, though, it is possible for long-run tax buoyancy to be different than 1 in any given period, due to specific circumstances that existed during that period. As argued by Dudine and Jalles (2018) and 
Pattichis (2020), if the long-run tax buoyancy is equal to 1, fiscal sustainability is ensured only if the percentage increase in government expenditure is equal to (or lower than) the percentage increase in aggregate income.

There is a growing body of empirical evidence in this area. Using data for 34 OECD countries over the period 1965-2012, Belinga et al. (2014) have shown that the long-run buoyancy of total tax revenue was greater than 1 in 14 out of 34 countries, suggesting positive implications for long-run fiscal sustainability. Their results also show that for 30 countries the long-run buoyancy was either statistically equal or greater than 1 .

Koester and Priesmeier (2017) have estimated tax revenue elasticities for the euro area countries and found that in 10 out of the 18 countries studied, the long-run elasticity was greater than 1. Using data for 107 countries, Dudine and Jalles (2018) have shown that the countryspecific long-run buoyancy of total tax revenue is statistically not different from 1 for 54 countries in their sample, while for 37 other countries it was statistically greater than 1 .

In a more recent study, Lagravinese et al. (2020) have estimated tax buoyancies (of total tax revenue and of four revenue categories) for 35 OECD countries over the period 1995-2016 and have shown that their estimates are lower compared to previous studies. Specifically, the country-specific long-run buoyancies are found to be below 1 in most cases, in contrast to previous studies that found many of them to be either 1 or above 1 (see, for example, the previously mentioned studies by Dudine and Jalles, 2018; and Belinga et al., 2014). Consequently, Lagravinese et al. (2020) argue that their findings have negative implications for long-run fiscal sustainability.

The studies referred to above by Lagravinese et al. (2020), Dudine and Jalles (2018) and Belinga et al. (2014) have provided estimates of long-run elasticities of total tax revenue for many of the countries under investigation in this paper. These are presented in Table 1 in the next section. However, Bulgaria was the only country that was not part of the sample of any of these papers. In a recent study, Tanchev and Todorov (2019) have estimated tax buoyancies (of total tax revenue and of four revenue categories) for Bulgaria over the period 1999-2017 and have shown that the long-run tax buoyancy of total tax revenue was below 1; their estimate is also given in Table 1.

Other notable recent studies include Mourre and Princen (2019) who have estimated tax revenue elasticities (of four revenue categories) for all EU countries over the period 2001-2013 using revenue data corrected for discretionary policy changes. In another notable recent study, Boschi and d'Addona (2019), using data from 1980-2013, have estimated tax elasticities for 15 European countries and have shown that the short-run elasticities of the four revenue categories considered, tend to be larger during recessions. Finally, Havranek et al. (2016), using revenue data adjusted for tax policy changes over the period 1995-2013, have estimated tax elasticities of four revenue categories in the case of Czechia. Some earlier studies include the work of Sobel and Holcombe (1996), Bruce et al. (2006), and Wolswijk (2009). For a more comprehensive literature review, the interested reader is directed to the various papers cited in the studies mentioned in this section.

As mentioned in the Introduction, the methodology of the present paper differs from the above-mentioned literature. The aim of this paper is not to estimate econometrically the actual tax revenue elasticities for the six CEE countries in the sample. Instead, the research approach here is to derive tax revenue elasticities that are consistent with a balanced government budget by utilising the recent contribution of Bajo-Rubio (2014). Bajo-Rubio (2014) has shown that:

$$
\hat{y}_{g b}=\dot{g} / e_{t y}
$$

where $\hat{y}_{g b}$ is the government balance-consistent economic growth rate, $\dot{g}$ is the rate of growth of government expenditure, and $e_{t y}$ is the total tax revenue elasticity/buoyancy. Pattichis (2020) has used this framework to calculate government balance-consistent growth rates for the euro area countries. 
Following a similar logic to Bajo-Rubio (2014), $\hat{y}_{g b}$ can be replaced by $\dot{y}$ (the actual growth rate of the economy) and after rearranging equation (1) obtain:

$$
e_{t y}^{g b}=\frac{\dot{g}}{\dot{y}}
$$

where $e_{t y}^{g b}$ is now the total tax revenue elasticity/buoyancy consistent with a balanced government budget. In the next section, these derived elasticities are compared to actual estimates given in other studies and the implications for fiscal sustainability are discussed. The reasoning in this paper is that, to support fiscal sustainability, the actual tax revenue elasticities/buoyancies must be greater than or equal to $e_{t y}^{g b}$. This implies that tax revenues are responsive enough to economic growth to help support long-run fiscal sustainability.

\section{Data, results, and discussion}

As the previous section demonstrates, the analysis requires estimates of the growth rate of government expenditure $(\dot{g})$ and the growth rate of income $(\dot{y})$ for each country. In this paper, these growth rates are estimated as the coefficient of the time trend in a regression of the natural logarithm of each variable on a constant and a time trend. The total tax revenue elasticity/buoyancy consistent with a balanced budget $\left(e_{t y}^{g b}\right)$ is then calculated as $\dot{g} / \dot{y}$. The data used in the analysis were taken from the AMECO macroeconomic database of the European Commission's Directorate General for Economic and Financial Affairs over the period 19952019. The data used for government expenditure was the index of real total expenditure of general government (code: OUTG, with 2015 as the base year), and the data used for income was the real Gross Domestic Product at constant prices (code OVGD, Gross Domestic Product at 2015 reference levels). The start of the sample period was dictated by the available data in the AMECO database for real total government expenditure for all countries in the sample and the desire to avoid the earlier period when these countries were socialist economies or in their initial period of transition. The end of the sample period was decided in order to avoid the impact of the Covid-19 pandemic.

The results of the estimated tax revenue elasticities consistent with a balanced government budget $\left(e_{t y}^{g b}\right)$ are summarised in Table 1 .

Looking at the results reported in Table 1, the first notable observation is that in most cases ( 4 out of the 6 countries considered), the tax revenue elasticity consistent with a balanced budget is lower than 1. This is because, over the observed period, the rate of economic growth of these four countries was greater than the growth rate of government expenditure. As argued in the previous section, tax revenues support long-run fiscal sustainability if the tax revenue elasticity/buoyancy is equal to or greater than 1. Over the observed period, though, the growth of government expenditure and aggregate income in these four countries implied a balanced budget-consistent tax elasticity of less than 1 . For the other two countries, the elasticity estimate is very close to 1 . In what follows, we discuss the results and their implications for each country. In the case of Bulgaria, the total tax revenue elasticity consistent with a balanced budget is 1.04. To support fiscal sustainability, the actual long-run tax revenue elasticity/buoyancy must be greater than or equal to this. Looking at the value of 0.89 estimated by Tanchev and Todorov (2019) this is not only below 1, but also below the value consistent with a balanced budget. Thus, in the case of Bulgaria over the observed period, long-run fiscal sustainability is not ensured, and further discretionary measures would need to be undertaken. For example, measures that lead to an increase in tax revenue elasticities will be helpful since fiscal sustainability can only be supported if economic growth leads to higher increases in tax revenues. For a discussion of factors that could influence the tax revenue elasticity see, for 
Table 1. Estimated tax revenue elasticities consistent with a balanced budget $\left(e_{t y}^{g b}\right)$.

\begin{tabular}{lcccc}
\hline \hline & $\dot{\boldsymbol{g}}$ & $\dot{\boldsymbol{y}}$ & $\boldsymbol{e}_{\boldsymbol{t} \boldsymbol{y}}^{\boldsymbol{g b}}$ & $\begin{array}{c}\text { Tax revenue elasticities } \\
\text { from other studies }\end{array}$ \\
\hline \hline Bulgaria & 3 & 2.88 & 1.04 & $0.89(\mathrm{TT})$ \\
Croatia & 1.43 & 1.81 & 0.79 & 1.033 (DJ) \\
Czechia & 2.26 & 2.6 & 0.87 & $0.884^{2}(\mathrm{LLS})$ \\
& & & & $1.016(\mathrm{DJ})$ \\
Hungary & 1.94 & 2.25 & 0.86 & $1.05(\mathrm{~B})$ \\
& & & & $0.863(\mathrm{LLS})$ \\
Poland & 3.29 & 3.83 & 0.86 & $0.922(\mathrm{DJ})$ \\
& & & & $0.861(\mathrm{~B})$ \\
& & & & $1.071(\mathrm{DJ})$ \\
Romania & 3.42 & 3.35 & 1.02 & $0.96(\mathrm{~B})$ \\
\hline \hline
\end{tabular}

Notes and sources (Table 1): $\dot{g}$ is the percentage growth rate of real government expenditure and $\dot{y}$ is the percentage growth rate of real GDP, estimated as explained in the main text. $e_{t y}^{g b}$ is the tax revenue elasticity consistent with a balanced budget, calculated as $\dot{g} / \dot{y}$.

${ }^{1}$ This column presents some tax revenue elasticities/buoyancies estimated in other studies; they are in relation to total tax revenue and refer to long-run estimates. They were taken from the following sources as indicated below (please note that the following studies have not included all of the above countries in their investigation):

TT: Tanchev and Todorov (2019, pg. 242).

DJ: Dudine and Jalles (2018), Tables A1a and A1b. The estimated values given for each country were not statistically different from 1.

LLS: Lagravinese et al. (2020), Table A6.

B: Belinga et al. (2014), Table 1. The estimated values given for Czechia and Poland were not statistically different from 1 , but the value for Hungary was statistically less than 1.

${ }^{2}$ This estimate was not statistically significant.

example, Dudine and Jalles (2018), Jalles (2017), Koester and Priesmeier (2017), Belinga et al. (2014), Lagravinese et al. (2020), and Pattichis (2020).

In the case of Croatia, the tax revenue elasticity consistent with a balanced budget over the observed period is 0.79 . As the actual tax revenue buoyancy for Croatia (of 1.033), estimated by Dudine and Jalles (2018), is greater than this value implies that the tax system is buoyant enough to help support long-run fiscal sustainability.

In the case of Czechia, Hungary and Poland, the tax revenue elasticities consistent with a balanced budget were $0.87,0.86$ and 0.86 , respectively. These values are almost identical to the actual tax revenue buoyancies estimated for these countries by Lagravinese et al. (2020), who argued that since their long-run estimates are below 1 implies that long-run fiscal sustainability cannot be ensured without further discretionary tax changes. However, the present paper argues that as the estimates of Lagravinese et al. (2020) are very similar to the tax revenue elasticities consistent with a balanced budget, then tax revenue was responsive enough to economic growth to ensure fiscal sustainability over the observed period (i.e., after considering the growth rate of government expenditure). This conclusion is further supported by the fact that the tax buoyancies estimated by Dudine and Jalles (2018) and Belinga et al. (2014) for these three countries were greater than the tax revenue elasticities consistent with a balanced budget.

In the case of Romania, the tax revenue elasticity consistent with a balanced budget over the observed period is 1.02. As the actual tax revenue buoyancy estimated by Dudine and Jalles (2018) is of the same magnitude, this suggests that the tax system was buoyant enough to support fiscal sustainability.

The overall conclusion from the analysis so far is that, except for Bulgaria, the tax revenue elasticities consistent with a balanced budget of all other countries were either below or very 
similar to the actual tax elasticities/buoyancies reported in other studies. This suggests that, over the observed period, tax revenues were responsive enough to economic growth to support fiscal sustainability.

In the academic literature, tax buoyancies or tax revenue elasticities are also estimated using nominal values of tax revenue and income. Therefore, to check the above results and conclusions, tax revenue elasticities consistent with a balanced budget were also estimated using the growth rates of nominal government expenditure and nominal aggregate income. The data for these variables also comes from the AMECO database and refers to the total expenditure of general government at current prices (code: UUTG, national currency units), and Gross Domestic Product at current prices (code UVGD, national currency units). The results are summarised in Table 2.

The conclusions based on the analysis presented in Table 2 are discussed below.

The first observation is that the tax revenue elasticities consistent with a balanced budget for most countries are now slightly higher than before and closer to 1 (the expected long-run equilibrium value). As other studies have shown, inflation may have a positive effect on tax revenue elasticities resulting in tax revenue elasticities in nominal terms being higher than those in real terms (see, for example, Lagravinese et al., 2020; and Dudine and Jalles, 2018).

In the case of Bulgaria, Croatia and Romania, the conclusions from the results presented in Table 2 remain the same as those based on the results reported in Table 1. In the case of Czechia, the conclusions also remain the same if the Dudine and Jalles (2018) and Belinga et al. (2014) estimates are used for comparison. However, the tax revenue elasticity consistent with a balanced budget is now 0.93 which is marginally higher than the actual tax buoyancy reported in Lagravinese et al. (2020), which implies that fiscal sustainability may not be supported if the Lagravinese et al. (2020) estimate is used for comparison (though the two values are very similar).

In the case of Hungary, the tax revenue elasticity consistent with a balanced budget is now 0.96. This is greater than the tax buoyancy estimates reported in Lagravinese et al. (2020) and Belinga et al. (2014) which suggests negative implications for long-run fiscal sustainability based on these comparisons. This conclusion, however, is not supported if the Dudine and Jalles (2018) estimate is used for comparison, as they have shown that their estimate is not statistically different from 1 .

In the case of Poland, the conclusions remain the same as those based on Table 1 if the Dudine and Jalles (2018) and Belinga et al. (2014) estimates are used for comparison. However, the tax revenue elasticity consistent with a balanced budget is now 0.92 which is marginally higher than the actual tax buoyancy reported in Lagravinese et al. (2020), which implies that tax revenues are not responsive enough to economic growth to support fiscal sustainability based on this comparison. However, the difference between the two values is very small.

Table 2. Estimated elasticities using the growth rate of variables measured in nominal terms

\begin{tabular}{lccc}
\hline \hline & $\dot{\boldsymbol{g}}$ & $\dot{\boldsymbol{y}}$ & $\boldsymbol{e}_{\boldsymbol{t y}}^{\boldsymbol{g b}}$ \\
\hline \hline Bulgaria & $12.44 / 7.74^{*}$ & $12.29 / 7.8^{*}$ & $1.01 / 0.99^{*}$ \\
Croatia & 4.33 & 4.7 & 0.92 \\
Czechia & 4.4 & 4.74 & 0.93 \\
Hungary & 7.05 & 7.36 & 0.96 \\
Poland & 6.38 & 6.91 & 0.92 \\
Romania & 17.82 & 17.75 & 1.004 \\
\hline \hline
\end{tabular}

Notes (Table 2): The variables are defined like those in Table 1 but, in this case, government expenditure and income (GDP) are measured in nominal (not real) terms. ${ }^{*}$ The starred estimates for Bulgaria exclude the years 1995 and 1996 as there appears to have been a structural break at that time (but as can be seen, the resulting estimates for $e_{t y}^{g b}$ are almost the same). 
The overall conclusion from the analysis based on the growth rates of variables measured in nominal terms is that, except for Bulgaria and probably Hungary, the tax revenue elasticities consistent with a balanced budget were either below or of a similar magnitude to the actual tax buoyancies reported in other studies. As argued previously, this result has positive implications for fiscal sustainability.

\section{Conclusion}

Tax revenue elasticities or tax buoyancies provide important information about the impact of economic growth on tax revenues and long-run fiscal sustainability. This paper has followed a novel approach of deriving tax revenue elasticities that are consistent with a balanced government budget for six CEE countries. These derived elasticities were then compared to actual estimates reported in other studies. The main conclusion from this comparison is that, for most cases considered, the tax revenue elasticities consistent with a balanced budget were either below or very similar to the actual tax revenue elasticities/buoyancies estimated in other studies. This suggests that, over the observed period, tax revenues were responsive enough to economic growth to support fiscal sustainability.

\section{Acknowledgements}

I would like to thank two anonymous referees of this journal for their valuable comments. I am, of course, responsible for any remaining errors.

\section{References}

Bajo-Rubio, O. (2014) Balance-constrained growth rates: generalizing Thirlwall's law, Applied Economics Letters, 21(9), 593-596.

Belinga, V., Benedek, D., de Mooij, R., and Norregaard, J. (2014) Tax Buoyancy in OECD Countries. International Monetary Fund, IMF Working Paper WP/14/110.

Boschi, M. and d'Addona, S. (2019) The stability of tax elasticities over the business cycle in European countries, Fiscal Studies, 40(2), 175-210.

Bruce, D., Fox, W. F., and Tuttle, M.H. (2006) Tax base elasticities: a multi-state analysis of long-run and short-run dynamics, Southern Economic Journal, 73(2), 315-341.

Deli, Y., Rodriguez, A. G., Kostarakos, I. and Varthalitis, P. (2018) Dynamic tax revenue buoyancy estimates for a panel of OECD countries. The Economic and Social Research Institute (ESRI) Dublin, ESRI Working Paper No. 592.

Dudine, P. and Jalles, J. T. (2018) How buoyant is the tax system? New evidence from a large heterogeneous panel. Journal of International Development, 30(6), 961-991.

Havranek, T., Irsova, Z., and Schwarz, J. (2016) Dynamic elasticities of tax revenue: evidence from the Czech Republic, Applied Economics, 48(60), 5866-5881.

Jalles, J. T. (2017) Tax buoyancy in Sub-Saharan Africa: An empirical exploration, African Development Review, 29(1), 1-15.

Koester, G. and Priesmeier, C. (2017) Revenue elasticities in euro area countries. European Central Bank, ECB Working Paper 1989.

Lagravinese, R., Liberati, P. and Sacchi, A. (2020) Tax buoyancy in OECD countries: New empirical evidence, Journal of Macroeconomics, 63, 103189.

Mourre, G. and Princen, S. (2019) The dynamics of tax elasticities in the whole European Union, CESifo Economic Studies, 65(2), 204-235. 
Pattichis, C. (2020) Government balance-consistent economic growth rates and their implications: A study of the euro area countries, European Journal of Government and Economics, 9(3), 220-231.

Sobel, R. S. and Holcombe, R. G. (1996) Measuring the growth and variability of tax bases over the business cycle, National Tax Journal, 49(4), 535-552.

Tanchev, S. and Todorov, I. (2019) Tax buoyancy and economic growth: Empirical evidence of Bulgaria, Journal of Tax Reform, 5(3), 236-248.

Wolswijk, G. (2009) The short and long-run tax revenue response to changes in tax bases, Economics Bulletin, 29(3), 1960-1970. 